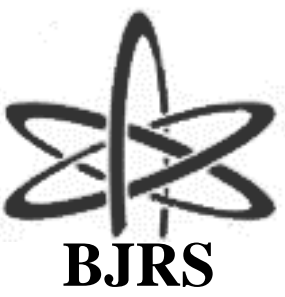
BRAZILIAN JOURNAL
$\mathrm{OF}$
RADIATION SCIENCES
08-02 (2020) 01-09

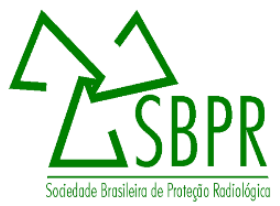

\title{
Quality control of small animal PET scanner: The Brazilian Scenario
}

\author{
GONTIJO, R.M.G. ${ }^{\mathrm{a}, \mathrm{b}}$; FERREIRA A.V. ${ }^{\mathrm{a} ;}$ SILVA J.B. ${ }^{\mathrm{a} ;}$ MAMEDE M. ${ }^{\mathrm{a}, \mathrm{b}}$ \\ ${ }^{a}$ Radiopharmaceuticals Research and Production Unit, Center of Nuclear Technology Development, 31270-901, \\ Belo Horizonte-MG, Brasil. \\ ${ }^{b}$ Department of Anatomy and Imaging, Federal University of Minas Gerais, 30130-100, Belo Horizonte-MG, Brasil. \\ rodrigo.gontijo@cdtn.br
}

\begin{abstract}
This work aims to evaluate the quality control program for small animal PET (positron emission tomography) scanners in Brazil. A questionnaire focused on type of small animal PET scanner and quality assurance program was prepared and sent to all Brazilian preclinical molecular imaging services that participated in the first Brazilian microPET/SPECT/CT users meeting held at the Federal University of Rio de Janeiro. The answers were compiled and descriptive statistic was applied. There are six preclinical molecular imaging services using PET scanner in Brazil. Five are in the southeastern region and one in the southern region. All services have a single PET device, but most of them have hybrids modalities with CT (computed tomography) and/or SPECT (single photon emission computed tomography). All services have knowledge of the NEMA NU 4/2008 publication specific to small animal PET equipments. However, most of them do not have a quality assurance program in place for their imaging systems. Although there is no quality assurance program for PET scanner implemented in most of the centers, there is a consensus between responsible of centers on their importance in preclinical molecular imaging research field.
\end{abstract}

Keywords: positron emission tomography (PET) small animal; quality control; NEMA NU 4-2008. 


\section{INTRODUCTION}

Positron emission tomography (PET) is an important molecular imaging modality. Its application on preclinical research has been increased in the last decades as a valuable tool for studying animal models of human disease and to contribute to the development of new radiopharmaceuticals or in studies of new applications of traditional radiopharmaceuticals [1].

Small-animal PET refers to imaging of animals such as rats and mice using specific PET scanner. Because of widespread use and commercial availability of preclinical PET scanners, the National Electrical Manufactures Association (NEMA) published its NU 4/2008 standards, a consistent and standardized methodology for measuring scanner performance parameters for smallanimal PET imaging [2].

In agreement with NEMA NU 4/2008 publication, PET performance should be evaluated by the following parameters [2]: i) Spatial Resolution; ii) Sensitivity; iii) Coincidence Events Rate; and iv) Image Quality. The NEMA NU 4/2008 presents all the methodological parameters and needs for the small-animals PET quality control.

Quality Control (QC) is a set of safety and performance tests executed periodically to assess whether the radiation measuring device continues to meet the requirements of current national and international resolutions and the reference values established during acceptance test [3]. QC is part of the quality assurance program that allows functional image acquisition for correct measurements and analysis.

In this context, it is important to perform a minimum set of quality tests for imaging technology that confirms their performance or indicates the need for corrective maintenance [4].

In Brazil, there are few preclinical PET in use and a standardization of quality control protocols are needed to harmonize their use in the research field [5]. Thus, the aim of this work was to evaluate the Brazilian scenario about quality control of small-animal PET scanners. 


\section{MATERIALS AND METHODS}

In order to evaluate the current scenario about preclinical PET performances available at the Brazilian research centers, a questionnaire with specific topics on equipment and quality assurance programs was prepared and applied. Briefly, the questionnaire inquiries about: 1) Equipment (preclinical PET systems) - quantity and type (manufacturer and model); and 2) Quality Assurance Program: implementation of PET scanner and dose calibrator (activimeters) quality control testing, as well as evaluation of NEMA NU 4/2008 publication use, specific phantoms availability for testing/analysis, and future implementation of quality assurance program (if not available at that moment).

This questionnaire was applied electronically via by e-mail to all preclinical molecular imaging research centers that participated on the first Brazilian microPET/SPECT/CT Users meeting held at the Federal University of Rio de Janeiro. The answers were compiled, and descriptive statistics were done for further analyses.

\section{RESULTS AND DISCUSSION}

All preclinical molecular imaging services replied the questionnaire. Figure 1 shows the geographic distribution of preclinical molecular imaging research centers in Brazil. There are six preclinical molecular imaging services using small-animal PET scanners. Among them, five are located in the southeastern region and one in the south region.

Table 1 shows the facilities and their respective preclinical PET technology installed. 


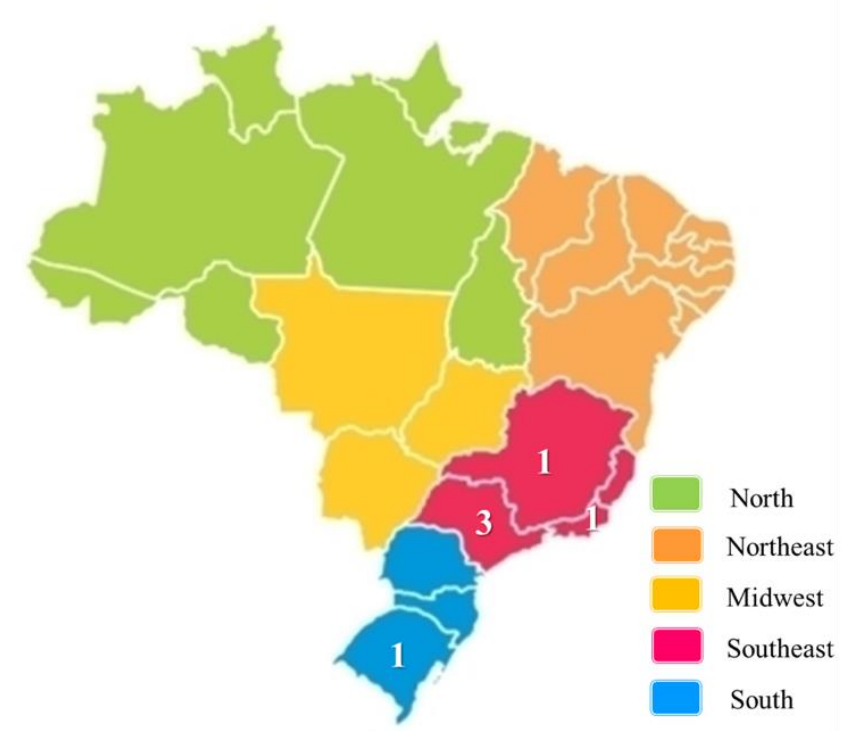

Figure 1: Geographic distribution of preclinical molecular imaging research centers in Brazil.

Table 1: Brazilian research centers and their respective preclinical PET systems.

\begin{tabular}{|c|c|c|c|c|}
\hline Centers & Region & State & Institution & Imaging System \\
\hline 1 & & & IPEN/CNEN (a) & $\begin{array}{c}\text { Albira } \\
\text { Trimodality PET/SPECT/CT }\end{array}$ \\
\hline 2 & & São Paulo & HCFMUSP (b) & $\begin{array}{c}\text { Triumph } ® \text { II LabPET } 8 \\
\text { Trimodality PET/SPECT/CT }\end{array}$ \\
\hline 3 & Southeast & & UNICAMP (c) & $\begin{array}{c}\text { Albira } \\
\text { Trimodality PET/SPECT/CT }\end{array}$ \\
\hline 4 & & Rio de Janeiro & UFRJ (d) & $\begin{array}{c}\text { Triumph } ® \text { II LabPET } 8 \\
\text { Trimodality PET/SPECT/CT }\end{array}$ \\
\hline 5 & & Minas Gerais & CDTN/CNEN (e) & Triumph® II LabPET Solo 4 \\
\hline 6 & South & $\begin{array}{l}\text { Rio Grande } \\
\text { do Sul }\end{array}$ & PUC-RS (f) & $\begin{array}{c}\text { Triumph }{ }^{\circledR} \text { II LabPET } 4 \\
\text { Bimodality PETCT }\end{array}$ \\
\hline
\end{tabular}

Note: (a) IPEN: Instituto de Pesquisas Energéticas; CNEN: Comissão Nacional de Energia Nuclear; (b) HCFMUSP: Hospital das Clínicas da Faculdade de Medicina da Universidade de São Paulo; (c) UNICAMP: Universidade de Campinas; (d) UFRJ: Universidade Federal do Rio de Janeiro; (e) CDTN: Centro de Desenvolvimento da Tecnologia Nuclear; CNEN: Comissão Nacional de Energia Nuclear; (f) PUC-RS: Pontifícia Universidade Católica do Rio Grande do Sul. 
All services have a single PET technology system, but most have hybrids modalities, with CT (computed tomography) and/or SPECT (single photon emission computed tomography). Triumph II platform with LabPET software is predominant (used in 4 services) and the Albira manufacturer are used in the other 2 services.

In table 2 it can be seen the internal procedures of quality assurance that are adopted in each center. Centers were not identified to preserve the internal routines adopted in each center.

Table 2: Quality assurance program implementation.

\begin{tabular}{ccccc}
\hline \multirow{2}{*}{ Centers $^{\S}$} & $\begin{array}{c}\text { Phantons (NEMA) } \\
\text { and sources }\end{array}$ & \multicolumn{2}{c}{ Quality Assurance Program Implementation } \\
\cline { 3 - 5 } & PEstem & Dose Calibrator & $\begin{array}{c}\text { Interest in } \\
\text { implementing }\end{array}$ \\
\hline a & No & No & Yes & Yes \\
b & Similar $*$ & No & Yes & Yes \\
c & Yes, all of them & Yes & Yes & Yes \\
d & Only Sources & Yes & Yes & $* *$ \\
e & In acquisition & No & Does not require & Yes \\
f & No & No & Yes & Yes
\end{tabular}

Note: §: Centers not identified for confidentiality; * Expression "similar phantom or sources" was used by the responsible of center that answered the questionnaire. The assessment of PET performance using similar phantoms with NEMA was not been found in the literature until now and makes comparison with other authors impossible; ** Information not provided.

Table 2 identifies the internal procedures done in main devices used in all molecular imaging preclinical centers. In addition, identifies if center have the interest in implementing the quality assurance in these devices and if own the phantoms and sources necessaries.

Only one - Service "c" - has quality assurance program implemented, and most of the molecular imaging research center do not have an imaging system quality assurance program in place. But, two of them have similar sources or specific phantom (not discriminated) for that purpose.

Regarding the dose calibrator, all services have a quality assurance program in place, except Service "e" (not required for his device). In this first step, the questionnaire allowed binary responses like yes or no. Tests to assess the performance of dose calibrators are described in the manufacturer's 
manual and also in CNEN standard 3.05 for clinical nuclear medicine services. Actually, in Brazil, there is no specific legislation that requires quality tests for dose calibrators in preclinical imaging laboratories.

All services have expressed interest in the subject and intend to establish the quality assurance program in the PET imaging system, except Service "d" (information not provided).

\section{DISCUSSION}

The National Electrical Manufactures Association (NEMA) produces technical documents regarding quality control procedures for various products, including medical equipment such as SPECT and PET for human (clinical) and for animals (preclinical). However, regulatory agencies in Brazil do not yet have any similar publication to establish in detail all necessary tests for preclinical equipment. In addition, there is a lack of knowledge for some methodological aspects of smallanimals PET.

Several research groups [6-11] have published articles where they discussed about performance of preclinical PET scanner. However, there are no long-term performance monitoring, manufacturer reference values or acceptance test nor any description on how such evaluations were actually performed.

This study revealed small-animal PET systems available in Brazil, as well as, information around feasibility of evaluating the performance of these imaging systems. In addition, this paper alerts all users for the importance of performing the quality control tests in their routines.

It is important to point out that all molecular imaging research centers in Brazil carry out preclinical studies with the objectives of new radiopharmaceuticals development and/or evaluation of new applications for well stablished radiopharmaceuticals in use. These requirements are part of the registration process at the Brazilian Health Regulatory Agency (ANVISA) [12].

So far, Brazil currently has eleven accelerators (cyclotron) authorized for PET radioisotopes production [13] and only two PET radiopharmaceuticals $\left({ }^{18} \mathrm{~F}-\mathrm{FDG}\right.$ and $\left.{ }^{18} \mathrm{~F}-\mathrm{Na}\right)$ are registered at ANVISA [14]. Among the accelerators, five have their own preclinical molecular imaging research center in the same place (all participated this survey). The relationship of proximity between the 
location of the preclinical PET system and the cyclotron unit is fundamental due to the short half-life of the radionuclides.

The molecular imaging centers carry out a variety of preclinical research but often fail to proceed to the clinical phase or not complete the ANVISA registration process. The reason for that can be especially due to absence of clinical center together with preclinical center or at least close in most of them. In addition to: (i) Radiopharmaceutical Synthesis: lack of production exclusively for research purposes; transportation cost of material radioactive when necessary. (ii) Clinical phase: PET scanner non-availability; nuclear medicine multi-professional staff. (iii) Registration Process: extensive list of criteria and many requirements not applicable to radiopharmaceuticals.

In spite of the radioisotope production capacity and growing demand for new radiopharmaceuticals for clinical use in Brazil, this study reveals that only six preclinical PET scanners may be insufficient to supply the diversity of pathologies that require diagnosis and/or follow-up.

Present scenario analysis allows strategies to propose a national program for small animal PET quality assurance. This work is an initial step in Brazil to verify the quality control of small animal PET for further standardization proposes.

\section{CONCLUSION}

There are few preclinical PET devices installed in Brazil and most are concentrating in southeast region. Only one research center has the quality assurance program implemented for PET scanner including the specific phantoms and the point source as recommended by NEMA NU 4/2008 publication. Although there is no quality assurance program for PET scanner implemented in most of the centers, there are a unanimous consensus between all interviewed on their importance in preclinical molecular imaging research field.

Summarizing, small animal PET has an important role in bridging the gap between basic, preclinical and clinical research and clinical application. Thus, the present study is an initial step to verify the quality control scenario of small animal PET in Brazil for future standardization proposes. 


\section{ACKNOWLEDGMENT}

The authors thank the staff of preclinical molecular imaging centers that participated of this study answering the questions.

\section{REFERENCES}

[1] YAO R.; LECOMTE R.; CRAWFORD E. Small-Animal PET: What is it, and why do we need it? Journal of Nuclear Medicine Technology. Vol. 40 nº3, pp.157-165. 2011.

[2] NEMA - National Electrical Manufacturers Association. Performance Measurements of Small Animal Positron Emission Tomographs. Rosslyn VA; 2008 Standards Publication NU 4-2008.

[3] CNEN - Comissão Nacional de Energia Nuclear. Requisitos de segurança e proteção radiológica para serviços de medicina nuclear, Norma CNEN NN 3.05. December, 2013.

[4] IAEA - International Atomic Energy Agency (IAEA). Quality Control Guidance for Nuclear Medicine Equipment. Guidelines of Radiation and Nuclear Safety Authority - STUK, 2010.

[5] GONTIJO, R. M. G. Proposta de Programa de Garantia da Qualidade para Imagem Molecular Pré-Clínica. 2019. 275 f. Tese (Doutorado em Ciência e Tecnologia das Radiações, Minerais e Materiais) - Centro de Desenvolvimento da Tecnologia Nuclear, Comissão Nacional de Energia Nuclear, Belo Horizonte, In Portuguese, 2019.

[6] GONTIJO, R. M. G., FERREIRA, A. V., SILVA, J. B., MAMEDE, M. Image quality assessment using NEMA NU 4/2008 standards in small animal PET scanner. Brazilian Journal of Radiation Sciences. 07 (2A). pp. 1-13. 2019.

[7] Begeron, M., CADORETTE, J., TÉTRAult, M. A., BEAUdOIN, J. F., LEROUX, J. D., FONTAINE, R. and LECOMTE, R., Imaging performance of LabPET APD-based digital PET Scanners for pre-clinical research. Physics in Medicine and Biology. v.59, pp. 661-678. 2014.

[8] RATIB, O., ZAID, H., PRASAD, R. NEMA NU-04-based Performance Characteristics of the LabPET-8TM Small Animal PET Scanner. IEEE Nuclear Science Symposium Conference Record. pp. 3654-3659. 2011. 
[9] GAITANiS, A., KAStis, G. A., Vlastou. E., BOUZIOTIS, P., VERGINIS, P., ANAGNOSTOPOULOS, C. D., Investigation of Image Reconstruction Parameters of the Mediso nanoScan PC Small-Animal PET/CT Scanner for Two Different Positron Emitters Under NEMA NU 4-2008 Standards. Molecular Imaging and Biology. v.19, pp. 550-559. 2016.

[10] DiSSElHORST, J. A., BROM, M., LAVERMAN. P., SLUMP, C. H., BOERMAN, O. C., OYEN, W. J. G., GOTHARDT, M., VISSER E. P., Image-Quality Assessment for Several Positron Emitters Using the NEMA NU 4-2008 Standards in the Siemens Inveon Small-Animal PET Scanner. The Journal of Nuclear Medicine. v.51 (4), pp.610-617. 2010.

[11] GOERTZEN A. L., NEMA NU 4-2008 Comparison of Preclinical PET Imaging Systems. The Journal of Nuclear Medicine. v.53 (8), pp.1300-1309. 2012.

[12] ANVISA - Brazilian Healthy Regulatory Agency. RDC n64. Radiopharmaceuticals registration. 2009.

[13] CNEN - Comissão Nacional de Energia Nuclear. Authorized installations. Available in: <http://www.cnen.gov.br/index.php/instalacoes-autorizadas-2>. September 2019.

[14] ANVISA - Agência Nacional de Vigilância Sanitária. Radiofármacos Reg. Available in: <http://portal.anvisa.gov.br/registros-e-autorizacoes/medicamentos/produtos/radiofarmacos>. June, 2020. 